\title{
O DOMÍNIO DE INTERNET E A SUA RELAÇÃO COM A PROPRIEDADE INTELECTUAL.
}

\section{THE INTERNET DOMAIN AND THEIR RELATIONSHIP WITH INTELLECTUAL PROPERTY.}

\author{
${ }^{1}$ Almir Garcia Fernandes
}

\section{RESUMO}

A localização empresária na internet é indispensável ao crescimento econômico. Portanto, importante estudar a relação dos domínios com a propriedade intelectual, demonstrando os aspectos econômicos da atividade virtual e o papel dos nomes de domínio, bem como a sua natureza jurídica. Ainda, importante apresentar resposta para as indagações: Como compatibilizar palavras dos domínios de internet quando semelhantes às expressões protegidas pela propriedade intelectual? Seria possível aplicar as mesmas regras de proteção da propriedade intelectual no universo físico e virtual? Para alcançar essas respostas será utilizado o método de pesquisa dedutivo. Os processos metodológicos serão o estudo dogmático jurídico e comparativo.

Palavras-Chave: Domínio de internet; clientela; propriedade intelectual; inovação tecnológica; estabelecimento virtual.

\begin{abstract}
The business location on the internet is indispensable to economic growth. Therefore, it is important to study the relationship of domains to intellectual property, demonstrating the economic aspects of virtual activity and the role of domain names, as well their legal nature. Still, it is important to answer the questions: How to match words from internet domains when similar to expressions protected by intellectual property? Is it possible to apply the same rules of intellectual property protection in the physical and virtual universe? To achieve these responses the deductive research method will be used. The methodological processes will be the legal and comparative dogmatic study.
\end{abstract}

Keywords: Internet domain; clientele; intellectual property; technologic innovation; Virtual establishment.

\footnotetext{
${ }^{1}$ Doutor em Direito Comercial pela Pontifícia Universidade Católica - PUC, São Paulo, (Brasil). Professor de Graduação e Pós-Graduação no Centro Universitário do Planalto de Araxá - UNIARAXÁ, Minas Gerais. E-mail: almir@uniaraxavirtual.com.br
} 


\section{INTRODUÇÃO.}

Na exploração das mais diversas atividades econômicas, a busca por destaque entre os concorrentes sempre motivou os empresários a esquadrinhar novas formas de colocar seus produtos no mercado para garantir uma parcela maior da clientela.

Nesse sentido, a internet mostra-se como instrumento necessário e indispensável àquele que pretende destacar seus negócios de seus concorrentes, de forma que não é exagero afirmar que o sucesso da atividade econômica do empresário contemporâneo encontra um elo cada vez mais íntimo com o universo virtual.

Deste modo, faz-se necessário realizar um estudo sobre a atuação empresarial neste universo, como forma de promoção econômica e proteção aos seus sinais distintivos, especialmente quanto à vinculação dos bens da propriedade intelectual com os registros de domínio dos sítios de internet.

Justifica-se este estudo, pois o registro de domínio, as marcas, o título de estabelecimento e os elementos de propaganda da empresa encontram distintas proteções jurídicas, tendo como ponto de conexão a sua utilização como elemento diferenciador da exploração da atividade econômica, o que garante ao empresário uma vantagem em relação aos seus concorrentes.

A pesquisa se mostra atual e relevante, pois percebe-se, a cada dia, a constituição de inúmeras empresas virtuais e a ampliação de diversas outras empresas físicas para atenderem também esse novo mercado, satisfazendo anseios de informalidade, praticidade, rapidez e diversibilidade, esperadas por seus consumidores, cada vez mais ávidos pelo comércio nessa nova tecnologia.

Nesse sentido, este texto, sem esgotar o assunto, tem a pretensão de buscar respostas para os seguintes questionamentos: quais aspectos econômicos relevantes envolvem a exploração do universo virtual e o papel dos nomes de domínio? Seriam os nomes de domínio simples endereço eletrônico para a aproximação do empresário com os consumidores, ou tratase efetivamente de um novo elemento do estabelecimento empresarial: o título de estabelecimento virtual? Como compatibilizar a exploração de determinas palavras dos domínios de internet quando elas encontrarem semelhanças com expressões protegidas pela propriedade intelectual? Seria possível aplicar as mesmas regras de proteção da propriedade intelectual tanto no universo físico quanto virtual? 
Será utilizado como método de pesquisa o dedutivo, que consiste em ensaio teórico, buscando analisar a bibliografia pertinente ao tema, além de relatos concretos contidos na doutrina e normas definidas em legislação própria, na tentativa de se trazer das regras gerais a solução para casos específicos.

Os processos metodológicos serão o estudo dogmático jurídico, visto a impossibilidade de um estudo profundo sem que se recorra à lei, à doutrina ou à jurisprudência neste sentido, descrevendo claramente as consequências da exploração de expressões protegidas no universo da propriedade intelectual com os domínios de internet; o comparativo, analisando e relacionando diferentes casos com o desenvolvimento da proteção jurídica à propriedade intelectual e aos registros de domínio de internet.

\section{1 - ASPECTOS ECONÔMICOS}

Em 1943 Asquini afirmou ser a empresa um negócio jurídico econômico que se apresenta sob diferentes perfis (subjetivo, objetivo, funcional e institucional). Declarou que "o conceito econômico de empresa refere-se essencialmente a economia de troca, pois somente na órbita da economia de troca, a atividade do empresário pode adquirir caráter profissional" (ASQUINI, 1996, p.104).

Desse modo, comprovou que os reflexos do desenvolvimento econômico são sentidos no universo jurídico, sobretudo no direito empresarial, pois as inovações tecnológicas que despontaram no final do século XIX (com a Revolução Industrial) e no século XX, aproximaram, mesmo que de forma assimétrica, os fenômenos econômicos, jurídicos e tecnológicos.

Foi nesse contexto que se descortinaram as primeiras regras internacionais de proteção às inovações tecnológicas, o que ocorreu a partir de 1883 com a realização da Convenção de Paris, "um dos mais antigos atos internacionais de caráter econômico multilateral que existem no mundo" (BARBOSA, 2013, p. 622).

A realização da Convenção de Paris estabeleceu princípios básicos que reduziram as divergências entre as mais diferentes legislações e regulamentações sobre a Propriedade Industrial, passando por posteriores revisões no século XX, até a consolidação do acordo TRIPS (Agreement on Trade-Related Aspets of Intelectual Property Rights), resultado da Rodada de negociações do Uruguai do GATT, que ocorreu no ano de 1994. 
Nesta mesma década de 90 a internet começou a se destacar como um mecanismo de exploração econômica. Segundo Almeida Filho e Castro (2005, p.25), a internet surgiu em 1969 como Projeto ARPANet, ligado ao Departamento de Defesa norte-americano, entretanto, "registra-se o início da década de 1990 como o começo da exploração comercial da Internet." com especial destaque para o comércio eletrônico, cuja definição de Newton De Lucca (2008, p. 52) não o restringe apenas às trocas realizadas na rede mundial de computadores:

(...) mas todas aquelas em que existe a utilização de uma ferramenta eletrônica para concretizá-las - emprestando-se assim, maior elastério ao significado de eletrônico de molde a abarcar não apenas o uso do computador no aperfeiçoamento das vontades negociais, mas também de outros objetos utilitários de que nos servimos para a comunicação recíproca, como o telefone, o celular, o rádio, a televisão, o faz, o telegrama, o radiograma, etc.

Para explorar economicamente esse novo universo virtual, também chamado de Nova Economia $^{2}$, os empresários acabaram por criar mecanismos que lhes aproximassem desta nova clientela. Assim, são criados os nomes de domínio de internet, como elementos virtuais que servem de instrumento para ligar as ofertas dos empresários aos interesses dos consumidores.

Os nomes de domínio possuem, portanto, a função econômica de um sinal distintivo tecnológico, de fácil associação ao empresário por parte de sua clientela. Trata-se de ferramenta tecnológica indispensável para o desenvolvimento da atividade empresarial, pois estes nomes representam o sinal distintivo virtual que permite aos consumidores buscarem produtos ou serviços que desejam na rede mundial de computadores.

Tecnicamente, isso ocorre porque cada computador ligado à internet, tanto em redes locais quanto na rede mundial, possui um IP, sigla em inglês para internet protocol, que representa um padrão de comunicação formado por uma sequência de números composta de 32 bites. ${ }^{3} \mathrm{O}$ nome de domínio portanto acaba sendo uma maneira mais fácil para acessar sites, pois quando é digitado, o servidor identifica o IP relacionado ao site, direcionando a comunicação virtual àquele endereço.

Desse modo, os nomes de domínio representam verdadeiros atalhos para que os “internautas" possam acessar o conteúdo que desejam. Entretanto, como todas as inovações,

\footnotetext{
${ }^{2}$ Segundo DE LUCCA (2008, p.37), "a nova economia estrutura-se a partir do desenvolvimento tecnológico e na forte competição entre os vários agentes econômicos, na busca da informação necessária à promoção daquele."

${ }^{3}$ Conforme explicação de ALECRIM (2011), disponível em: http://www.infowester.com/ip.php. Acesso em 20 de junho de 2016.
} 
demandam soluções para a resolução de eventuais problemas que emergem de sua utilização, tais como a concorrência desleal e as tentativas de violação fraudulenta.

Isso ocorre principalmente porque a apresentação de inovações tecnológicas acaba se mostrando como um propulsor eficiente para novas modalidades de concorrência, em especial a concorrência virtual.

Com o crescimento do mercado virtual, cresceram também as tentativas de aproveitarse indevidamente desta nova rede de consumo, seja através de prejuízo direto ao concorrente, ou mesmo pela prática de delitos de furto de informações, valores, créditos, etc. Tal fato se comprova através de estudo especifico realizado pelo Centro de Estudos, Resposta e Tratamento de Incidentes de Segurança no Brasil (cert.br), que cataloga as ocorrências sobre incidentes na internet, relacionados especialmente a ataques a sites, scans e tentativas de fraude. Segundo dados estatísticos, no ano de 2000, o número de incidentes reportados foi de 5.997; no ano de 2005 esse número passou para 68.000, já em 2014 foram registrados 1.047.031. ${ }^{4}$

Há, portanto, um crescimento exponencial do mercado virtual que, em contrapartida, também leva à prática de violações e fraudes por aqueles que pretendem se aproveitar indevidamente nesta nova economia.

Tal como ocorre no ambiente físico, os empresários buscam destacar-se de seus concorrentes, na oferta de produtos e de serviços. Essa busca por uma posição de destaque, muitas vezes não está acompanhada de atitudes lícitas, especialmente no meio virtual, pois os meios de coibição e as regulamentações dessa nova tecnologia ainda estão em fase de construção.

Dentre estes atos também são reconhecidos aqueles que violam diretamente direitos da propriedade intelectual, pois atualmente não é possível se falar em ofertas de produtos, exploração da imagem e comercialização de softwares desvinculados da realidade virtual.

O comércio de produtos contrafeitos deixou de ser uma realidade das ruas populares e praças das grandes cidades e adotou a internet como um novo mecanismo, pois o meio virtual se apresenta como um eficiente instrumento para divulgação de produtos e serviços e valorização das empresas, entretanto, também se mostra como principal via de atuação de free riders.

Ao apresentar os fundamentos econômicos da proteção à propriedade intelectual Brancher entende que, para tecnologia e concorrência "alcancem um resultado consistente, é

\footnotetext{
${ }^{4}$ Dados oferecidos por Centro de Estudos, Resposta e Tratamento de Incidentes de Segurança no Brasil. Disponível em: http://www.cert.br/stats/incidentes/. Acesso em 20 de agosto de 2016.
} 
imperativo que as empresas destinem parte de seus recursos (dinheiro, mão de obra e tempo) em atividades de inovação constantes, visando transformar o conhecimento existente em informação com maior valor agregado" (2010, p. 31).

Assim, a proteção do mercado como um todo e em especial o mercado virtual também passa pela proteção dos sinais distintivos empresariais, como o nome de domínio, as marcas e demais bens da propriedade intelectual, demandando atuação específica dos empresários e do poder público na criação de mecanismos capazes de evitar a atuação econômica indevida.

\section{2 - OS NOME DE DOMÍNIO, SUA NATUREZA JURÍDICA E O ESTABELECIMENTO VIRTUAL}

Os nomes de domínio são obtidos através de registro realizado junto ao Comitê Gestor da Internet para a exploração de qualquer atividade, empresaria ou não, no universo virtual. Atualmente vem ganhando uma importância cada vez maior no meio empresarial, pois acabam por determinar "a visibilidade da empresa e a capacidade de ela ser localizada; quando não imprimem também valor, agindo como marca virtual" (PINHEIRO, 2008, p. 99), transcendendo a mera característica de um simples endereço virtual da empresa.

São, portanto, uma representação nominal do endereço virtual do empresário (composto por uma sequência de números formada por 32 bites) que a clientela se utiliza para localizar atividades, produtos e as próprias empresas na internet. Estes endereços eletrônicos, também conhecidos pela palavra websites são formados por um conjunto de páginas web, acessíveis na internet pelo protocolo HTTP (Hyper Text Transfer Protocol - Protocolo de Transferência de Hipertexto).

Podem ser considerados como elemento incorpóreo do estabelecimento empresarial, principalmente por sua proximidade com os conceitos de ponto ou estabelecimento virtual, como verdadeira derivação da proteção legal conferida ao ponto comercial.

Nesse sentido vale lembrar a definição de ponto comercial, ou empresarial, oferecida por Gladston Mamede (2004, p.252):

O ponto empresarial é o estabelecimento considerado por sua situação geográfica, por sua localização, o que implica atestar para as realizações entre a empresa - ou determinado estabelecimento empresarial - e sua vizinhança, sua freguesia, no sentido há pouco estudado. Sua proteção parte da constatação de que essa localização possui relevância 
para a atuação empresarial e para o sucesso empresarial, compondo o benefício do mercado (goodwill of trade).

Desse modo, o endereço eletrônico do empresário eleva o conceito de ponto comercial, no seu aspecto virtual, a um elemento de diferenciação do empresário em relação aos seus concorrentes, perceptível por sua clientela. Há uma grande diferença entre o ponto comercial físico, que não possui qualquer ligação com a propriedade intelectual, pois trata-se de mero endereço e o ponto virtual, pois no caso deste último o endereço é registrado como nome de domínio, o que confere uma posição estratégica ao empresário, visualmente distintivo, em relação a sua clientela e seus fornecedores.

Isso porque no ambiente virtual os consumidores e fornecedores buscam a localização do empresário através do seu nome de domínio, que guarda estrita conexão com o título de estabelecimento, passível de associação à propriedade intelectual.

Assim, em comparação com os elementos do estabelecimento empresarial é possível afirmar que o nome de domínio "em tudo assemelha-se ao título de estabelecimento, e como tal, merece proteção" (FORGIONI, 2008, p. 515). Nesse sentido vale lembrar a definição clássica de Vivante (2007, p.149), para quem "a denominação constitui um direito patrimonial, cujo valor econômico se torna notável para o comércio, quando se soube conquistar por meio da habilidade e da honestidade uma larga clientela". ${ }^{5}$

Essa comparação entre o nome de domínio e o título de estabelecimento parece acertada, pois, em ambos os casos tem-se um sinal distintivo que identifica o empresário. Paula Forgioni (2008, p. 515) ainda destaca que o nome de domínio:

1 - permite que o cliente situe-se em um "local" [virtual] para adquirir os produtos ou serviços oferecidos pelo agente econômico;

2 - permite a identificação desse "local", distinguindo-o de outros; e

3 - atua como importante elemento coletor de clientela;

A referência virtual do empresário tem demonstrado significativa importância no desempenho de sua atividade econômica "em função do vulto do empreendimento, do tipo de

\footnotetext{
${ }^{5}$ Devemos lembrar que Vivante não usava a expressão título de estabelecimento, mas sim a expressão denominação comercial, adequada à época.
} 
atividade, do perfil da clientela potencial" (COELHO, 2012, p. 163) representando, na realidade, um fator estratégico com relação àqueles a quem se destinam os negócios.

O comércio no meio virtual cresceu em importância econômica e, na medida em que se desenvolve, importa em novas relações jurídicas. Nesse contexto, a maior parte da doutrina optou por chamar de estabelecimento virtual o local onde as relações empresariais são desenvolvidas a partir do acesso dos consumidores via transmissão e recepção econômica de dados.

Fábio Ulhoa Coelho critica esse conceito, pois, segundo ele, "não se pode evidentemente, perder-se de vista o caráter de algo artificial deste expediente linguístico, que, por definição, não descreve algo pelo que é, mas por algum semelhante” (2012, v.3, p. 49). Por outro lado, ainda não existe uma definição específica quanto a nomenclatura do ambiente empresarial no universo virtual, por isso, a opção adequada para referir-se ao mesmo é a utilização do termo estabelecimento virtual, para os estabelecimentos empresariais neste meio e título de estabelecimento virtual, para os nomes de domínio dos sites das empresas.

$\mathrm{Na}$ maioria dos casos, o estabelecimento virtual representa uma extensão das atividades que a empresa exerce no ambiente físico, entretanto, nem sempre isso acontece, pois já é possível constatar a presença de Empresas totalmente virtuais, ou seja, que não possuem sedes físicas realizando seus negócios. ${ }^{6}$

São justamente essas empresas, cuja exploração da atividade econômica ocorre no ambiente virtual, sejam como extensão da atividade econômica exercida no ambiente físico ou puramente virtuais, que apresentam proximidade do nome de domínio aos bens tutelados pela Propriedade Intelectual.

Isso ocorre porque o registro da atividade no ambiente virtual depende de um registro de domínio, que inevitavelmente apresenta um aspecto nominativo, tal como ocorre com os títulos de estabelecimento das empresas no ambiente físico.

Os nomes de domínio apresentam-se como verdadeiro sinal distintivo do empresário, com funções de preservar a vantagem competitiva no ambiente virtual; fomentar o progresso técnico e científico e proteção ao consumidor, pois a associação ao empresário e aos produtos que ele comercializa são uma característica própria dos sinais distintivos.

\footnotetext{
${ }^{6}$ PINHEIRO (2008 p. 49), destaca: "Inicialmente, é importante ressaltar que Empresa Virtual não é o mesmo que extensão virtual de empresa real. Enquanto esta refere-se a empresas que efetivamente existem no mundo real, física e juridicamente, aquela muitas vezes não consta sequer com uma sede física."
} 
Desta maneira, é possível entender que a natureza jurídica do domínio de internet é de título de estabelecimento e não de nome empresarial, como alguns autores defendem ${ }^{7}$, pois trata-se simplesmente de um referencial simbólico e não de um elemento de personalidade do empresário. Lembrando que o nome empresarial é reconhecido como um sinal distintivo do empresário e que pode encontrar semelhança tanto com o título de estabelecimento quanto com marca registrada, possuindo inclusive proteção especial nas relações de concorrência ${ }^{8}$.

Entretanto o nome empresarial possui uma natureza jurídica que vai além de um mero sinal distintivo, pois ele também é elemento da personalidade jurídica do empresário, tal como destaca Carvalho de Mendonça (2008, p. 13): "se a pessoa exerce a profissão mercantil, nessa esfera de atividade é individualizada pelo nome comercial, sob o qual faz transações, adquire direitos contrai obrigações e vai aos tribunais acionar ou se defender".

Portanto, são distintas as aplicações do nome empresarial, enquanto um elemento da personalidade jurídica da empresa do seu título de estabelecimento, que inclusive não goza mais de registro próprio, sendo apenas um elemento visual distintivo do empresário, sem as mesmas atribuições do nome empresarial. Por isso, entende-se mais adequada a vinculação da natureza jurídica nome de domínio com o título de estabelecimento do que com o nome empresarial.

Aos nomes de domínio, portanto, inserem-se as mesmas regras de proteção conferidas aos títulos de estabelecimento quanto aos aspectos concorrenciais, ainda, "a exclusividade dos nomes de domínio tem sido assegurada pelos tribunais e pelos centros de arbitragem internacional selecionados pelo ICANN (Internet Corporation for Assigned Names and Numbers)" (CARVALHO, 2009, p. 622), estando reconhecidos como elemento incorpóreo do estabelecimento empresarial.

\section{3 - O DOMÍNIO de INTERNET E A SUA RELAÇÃo COM A PROPRIEDADE INTELECTUAL.}

Demonstrada a hipótese de que os nomes de domínio possuem natureza jurídica de títulos de estabelecimento virtual, resta agora buscar as situações práticas que envolvem esses

\footnotetext{
${ }^{7}$ Nesse sentido é o posicionamento de RÜCKER(2016): "Pela própria essência do nome de domínio, que representa o endereço eletrônico de determinada empresa ou produto, configurando o caminho que o usuário da rede utiliza para encontrá-lo, temos uma similitude ao nome empresarial"

${ }^{8}$ Tal como previsto no art. 195, V da Lei 9.279/96: Comete crime de concorrência desleal quem: (...) V. usa, indevidamente, nome comercial, título de estabelecimento ou insígnia alheios ou vende, expõe ou oferece à venda ou tem em estoque produto com essas referências; (...)
} 
elementos incorpóreos com bens protegidos pela propriedade intelectual. Seria possível afirmar que as marcas, sinais de propaganda e os domínios de internet possuem relação entre si, ou seja, os detentores da propriedade intelectual também possuem o direito de registrá-la como nome de domínio com a exclusão de terceiros, ou são institutos completamente diversos?

Deve-se adiantar que com o crescimento do comércio virtual também houve um significativo crescimento de registro de nomes de domínio que, muitas vezes, guardam semelhanças em relação a marcas, nomes empresariais, nomes civis, pseudônimos, títulos de obras.

Quanto os registros de domínio são feitos pelos titulares destes bens da propriedade intelectual, trata-se de exercício regular do direito de exploração econômica de ativos intangíveis, entretanto, em alguns casos, os registros de domínio são feitos por free rides não detentores da propriedade intelectual.

Como não há controle específico pela FAPESP ou pelo CGI, muitos nomes de domínio são registados apresentando semelhanças, na íntegra ou em partes, com bens da propriedade intelectual. Na maioria dos casos, tais registros são feitos com intenção de induzir em erro o consumidor, ou aproveitar-se de forma parasitária do sucesso empresarial de terceiros, prejudicando o titular dos bens da propriedade intelectual.

Associa-se a esta utilização indevida a pratica de crimes como a concorrência desleal, a reprodução não autorizada de direito autoral e de marca, em especial quando os usuários da rede procuram os produtos ou marcas desejadas através da associação de palavras em mecanismos de busca na internet.

Isso ocorre porque os consumidores, e os próprios empresários, em regra, buscam os produtos, serviços, fornecedores, referências, etc., através de associações de palavras em aplicativos de busca, sejam através de computadores, celulares, tablets ou outros mecanismos. Isso propicia, em muitos casos, o aproveitamento daqueles que, indevidamente, utilizam-se de palavras já exploradas por seus concorrentes, estejam elas protegidas, ou não, pela propriedade intelectual. ${ }^{9}$

\footnotetext{
${ }^{9}$ DANTES (CONPEDI, 2015, p.9) explica as hipóteses de associação de palavras em mecanismos de busca: Cada um dos muitos web sites de busca na rede pode ter um programa de computador próprio com um algoritmo específico para a localização de outros sites na internet. Normalmente, a pessoa que quer localizar algum web site sobre determinado assunto digita a palavra que se relaciona com o assunto (ou com o produto, caso esteja à procura de um fornecedor). $\mathrm{O}$ algoritmo do programa de computador do buscador gera uma lista indexada de web sites que se relacionam com a palavra que foi o objeto da busca. A lista gerada pelo buscador costuma colocar em primeiro lugar aquele web site que mais relação teria com a palavra que foi objeto da busca. Como cada programa usado por cada buscador pode adotar um algoritmo diferente dos demais, as listas ordenadas e indexadas dos web sites geradas pelos vários buscadores da internet não são necessariamente iguais.
} 
Scudeler (2013, p. 138) destaca a importância do nome de domínio e sua relação como sinal de identificação do empresário e os direitos da Propriedade Industrial:

O nome de domínio é, portanto, o nome utilizado para se localizar determinada empresa que possui um site ou uma home page na internet. Neste contexto, é pacífico o entendimento de que os nomes de domínio, embora tenham surgido como um meio de endereçamento na Internet, atuam como sinais de identificação dos agentes que exercem atividade nesse espaço e cuja utilização tem suscitado conflitos com outros sinais tradicionalmente protegidos pela propriedade intelectual.

Assim, a palavra principal que está associada ao registro de domínio acaba por apresentar-se como objeto de localização do próprio empresário em todo o universo virtual, um verdadeiro instrumento tecnológico de referência à sua clientela.

Nesse sentido, destaca FORGIONI (2008, p. 516.) que "o nome de domínio deve encontrar proteção em nosso ordenamento semelhante àquela reservada ao título de estabelecimento, sob pena de incentivo à atuação ineficiente de free riders e desestímulo ao fluxo de relações econômicas", uma vez que em ambos os casos temos um título específico de estabelecimento empresarial que se destaca aos consumidores e fornecedores.

Entretanto, diferente dos títulos de estabelecimento físicos, que não possuem registro próprio, os nomes de domínio possuem uma proteção mais ampla, pois são dotados de registro específico junto ao Comitê Gestor da Internet ${ }^{10}$, que atua em conjunto com a FAPESP.

Por outro lado, os nomes de domínio também podem conter elementos textuais que lhes aproximam das marcas e de expressões de propaganda protegidas pelo Direito Autoral, restando dúvida quanto às regras a serem aplicadas em casos concretos. Seria possível aplicar as mesmas regras de proteção da propriedade intelectual tanto no universo físico quanto virtual?

Antes de apresentar uma resposta direta a esse questionamento é importante lembrar que uma característica específica dos nomes de domínio análoga às marcas, qual seja a aplicação do princípio first come first served, first to file, first to use, ou também chamado de princípio da prioridade, pelo qual aquele que primeiro promoveu o registro do nome de domínio terá o direito de explorá-lo.

\footnotetext{
${ }^{10}$ Vale lembrar que o Comitê Gestor da internet emitiu em 15 de maio de 1998 a Resolução ${ }^{\circ}$ 002, delegando à FAPESP (Fundação de Amparo à Pesquisa do Estado de São Paulo) a competência para a realização de registros de nomes de domínio (art. 1 Resolução 002/98).
} 
Esse princípio acabou por ser reconhecido pelo STJ no julgamento de 05 de setembro de 2013 do Recurso Especial 658789 / RS, que teve como relator o Ministro Ricardo Villas Bôas Cueva, destacando inclusive o elemento de boa-fé àquele que primeiro promoveu o registro do domínio da internet, prevalecendo o registro, mesmo no caso de anterioridade do registro no nome empresarial na Junta Comercial.

Destaca-se da ementa do julgamento:

1. A anterioridade do registro no nome empresarial no órgão competente não assegura, por si só, ao seu titular o direito de exigir a abstenção de uso do nome de domínio na rede mundial de computadores (internet) registrado por estabelecimento empresarial que também ostenta direitos acerca do mesmo signo distintivo.

2. No Brasil, o registro de nomes de domínio na internet é regido pelo princípio "First Come, First Served", segundo o qual é concedido o domínio ao primeiro requerente que satisfizer as exigências para o registro.

3. A legitimidade do registro do nome do domínio obtido pelo primeiro requerente pode ser contestada pelo titular de signo distintivo similar ou idêntico anteriormente registrado - seja nome empresarial, seja marca.

4. Tal pleito, contudo, não pode prescindir da demonstração de má-fé, a ser aferida caso a caso, podendo, se configurada, ensejar inclusive o cancelamento ou a transferência do domínio e a responsabilidade por eventuais prejuízos.

5. No caso dos autos, não é possível identificar nenhuma circunstância que constitua sequer indício de má-fé na utilização do nome pelo primeiro requerente do domínio. $^{11}$

Veja-se que neste caso específico a proteção conferida ao registro de domínio transcendeu a mera proteção de títulos de estabelecimento, superando inclusive a proteção que se confere ao nome empresarial registrado na Junta Comercial. Deve-se destacar que a regra geral de proteção aos títulos de estabelecimento nas relações corpóreas (ou não virtuais) segue orientação diversa, pois, em regra, deveria prevalecer a proteção do nome empresarial em detrimento do título de estabelecimento. ${ }^{12}$

\footnotetext{
${ }^{11}$ Disponível em:

http://www.stj.jus.br/SCON/jurisprudencia/doc.jsp?livre=DOM\%CDNIO+NA+INTERNET\&\&b=ACOR\&p=tru e\&t=JURIDICO\&l=10\&i=2. Acesso em 30 de julho de 2016.

${ }^{12}$ Nesse sentido veja o Recurso Especial 30.363/SC, julgado em 11 de outubro de 1993 pela $4^{\text {a }}$ Turma do STJ em que o Ministro Sálvio de Figueiredo Teixeira assim declarou: "a empresa que insere em sua denominação, ou como nome de fantasia, expressão peculiar, manifestando, assim, inequívoco desejo de que sirva a identifica-la perante a generalidade de pessoas, passa, a parit do registro respectivo, a ter legitimidade para adotar referida expressão como sinal externo distinto e característico e impedir que outra empresa que atue no mesmo ramo de
} 
Entende-se que essa diferença de tratamento é proveniente da influência geográfica que as atividades econômicas possam exercer. No caso da comparação entre o nome empresarial e o título de estabelecimento em locais físicos, é notório que o Registro do primeiro na Junta Comercial lhe confere proteção em uma Unidade Federativa específica. Já na comparação entre o nome empresarial e o registro de domínio, a influência geográfica deste último é muito maior, atingindo a todos aqueles que estejam conectados, inclusive, internacionalmente.

O nome de domínio, portanto, insere-se dentro da proteção específica contra a concorrência desleal, seguindo regras análogas à proteção ao título de estabelecimento e as insígnias do empresário de que é formado, entretanto, assume regra específica quanto a sua utilização, tendo em vista o momento em que foi requerido seu registro de utilização na rede mundial de computadores, em respeito ao princípio da prioridade.

Assim como se percebe da própria proteção dos titulares de bens da Propriedade Intelectual, o titular do nome de domínio também possui o direito de impedir a sua utilização indevida, entretanto, segue parâmetros gerais provenientes das regras que regulamentam aqueles bens incorpóreos, bem como princípios próprios para sua proteção de acordo com a anterioridade de seu registro, a natureza da atividade exercida e sua influência geográfica.

Justamente nesse ambiente virtual é possível destacar os elementos que podem ensejar violação da concorrência, e, principalmente, semelhanças com marcas devidamente registradas, sejam elas notórias ou não.

Nessas situações, o princípio da prioridade não será reconhecido de forma absoluta, havendo inclusive situações fáticas em que será mitigado, especialmente quando encontrar semelhanças com a marca registrada, dentro da respectiva classe, ou das marcas notórias, independente da natureza da atividade econômica.

Na prática já foi objeto de julgamento pelo Tribunal de Justiça de Minas Gerais agravo de instrumento no qual os litigantes disputavam pelo direito de utilizar-se da palavra "capricho", devidamente registrada no INPI como marca de revista jovem feminina.

Destaca-se do julgamento o entendimento do Tribunal Mineiro no sentido de proteger a marca registrada face ao registro de domínio com violação do direito marcário:

comércio como tal a utiliza. Disponível em: https://ww2.stj.jus.br/processo/pesquisa. Acesso em 20 de agosto de 2016. 
EMENTA: AGRAVO DE INSTRUMENTO - PROPRIEDADE INDUSTRIAL DOMÍNIO DE INTERNET- REGISTRO DA MARCA NO INPI - POSSIBILIDADE DE CONFUSÃO ENTRE OS CONSUMIDORES. Incompatível a utilização da mesma expressão utilizada por outrem, visto que as empresas possuem mesmo ramo de atividade e a marca deve ser preservada para que não cause confusão aos consumidores e nem prejudique a livre concorrência. AGRAVO DE INSTRUMENTO CV Nº 1.0687.12.0060953/001 - COMARCA DE TIMÓTEO - AGRAVANTE(S): D VIEIRA COSTA ME AGRAVADO(A)(S): EDITORA ABRIL S/A ${ }^{13}$

Segue-se então que a proteção adjudicada ao nome de domínio apresenta elementos íntimos de ligação com o título de estabelecimento, merecendo portanto proteção legal nos mesmos moldes deste último, principalmente no que diz respeito a coincidência gramatical com marcas devidamente registradas no INPI.

Nesse sentido, em agosto de 2001, a Associação Brasileira da Propriedade Intelectual - ABPI - apresentou a Resolução n. 13, após estudar e debater o assunto no seio de suas Comissões de Marcas e de "Software" e Informática, ofertou sete conclusões, das quais destacam-se as quatro primeiras:

1- A marca confere a seu titular uma exclusividade de uso no que concerne ao seu emprego como elemento identificador de produtos e serviços, seja no meio real, seja no ambiente virtual composto por todo e qualquer meio de comunicação, notadamente a Internet, como explicitado na justificação do Projeto de Lei 2.300/00 e nas resoluções relativas às questões Q155 e Q164 da AIPPI - Association Internationale pour la Protection de la Propriété Intellectuelle;

2 - Sempre que colidir com marca anteriormente registrada ou usada por outrem, o nome de domínio sujeita seu titular à invalidação do registro, ao bloqueio e abstenção do seu uso (inclusive a título cautelar ou de antecipação de tutela) e ao pagamento de uma indenização, sem prejuízo das demais medidas cíveis e criminais que forem cabíveis;

3 - A notoriedade ou alto renome não são condições imprescindíveis para que as marcas sejam protegidas na Internet contra a imitação ou reprodução (parcial, total ou com acréscimo), mas demonstram o dolo do agente ao usurpá-las e permitem a exacerbação das medidas sancionatórias;

\footnotetext{
${ }^{13}$ Disponível em: http://jurisprudencia.s3.amazonaws.com/TJ-MG/attachments/TJMG_AI_10687120060953001_4ead6.pdf?Signature=1180Y1GpTIcZq3WYNQh0ZVLtJe0\%3D\&Expires=14080 20413\&AWSAccessKeyId=AKIAIPM2XEMZACAXCMBA\&response-content-type=application/pdf\&x-amzmeta-md5-hash=ebd7a2ab7c4c695a4326e1c1b6f60162. Acesso em 11 de agosto de 2016.
} 
4 - A atual legislação já confere proteção às marcas em todo e qualquer meio no qual as mesmas podem ser postas em evidência como sinais identificadores de produtos e serviços, não tendo a jurisprudência hesitado em, acertadamente, aplicar a legislação marcária para solucionar conflitos entre marcas e nomes de domínio; ${ }^{14}$

Entretanto, o direito que o titular da marca possui de impedir a exploração de um determinado nome de domínio deve respeitar o princípio da especialidade, ou seja, não será lícito ao titular da marca impedir a utilização de um nome de domínio de internet cuja atividade econômica explorada não esteja vinculada a classe específica de registro junto ao I.N.P.I.

Apenas as marcas notórias e as marcas de alto renome possuem proteção em todas as classes de produtos e serviços, portanto, poderiam também impedir a exploração comercial de nomes de domínio de internet independente do conteúdo por elas apresentados.

Em qualquer destas hipóteses é bom lembrar que não há um controle prévio do CGI ou da FAPESP quando do requerimento dos registros de domínio na internet. Entretanto, em outubro de 2010 foi criado o SACI - Adm., ou seja o Sistema Administrativo de Conflitos de Internet relativos a nomes de domínios sob o ".br", que tem por objetivo a solução de litígios entre o titular de nome de domínio no ".br" (denominado "Titular") e qualquer terceiro (denominado "Reclamante") que conteste a legitimidade do registro do nome de domínio feito pelo Titular.

Esse procedimento é implementado por instituições previamente aprovadas pelo NIC.br e devidamente credenciadas, que aplicarão seus respectivos Regulamentos aprovados pelo NIC.br. Dentre estas instituições estão a Associação Brasileira da Propriedade Intelectual - ABPI, a Câmara de Comércio Brasil - Canadá - CCBC; e a Organização Internacional da Propriedade Intelectual - WIPO. O Reclamante escolherá uma das instituições credenciadas e solicitará à instituição escolhida a abertura de procedimento do SACI-Adm.

Ao final a decisão proferida no procedimento do SACI-Adm poderá determinar que o nome de domínio objeto do conflito seja transferido ao Reclamante ou seja cancelado. ${ }^{15}$

Importante lembrar que tal procedimento administrativo somente poderá ser instaurado se comprovado que o titular do domínio estiver intencionalmente tentando atrair, com objetivo de lucro, usuários da Internet para o seu sítio da rede eletrônica ou para qualquer

\footnotetext{
${ }^{14}$ Disponível em: http://www.abpi.org.br. Acesso em 22 de agosto de 2016.

${ }^{15}$ Nesse sentido ver o regulamento do SACI - Adm. Disponível em: http://registro.br/dominio/saci-admregulamento.html. Acesso em 22 de agosto de 2016.
} 
outro endereço eletrônico, criando uma situação de provável confusão com o sinal distintivo do Reclamante.

Nesse sentido destaca-se mais uma vez a natureza jurídica de título de estabelecimento ao nome de domínio, pois a partir daí também pode ser incluído na proteção contra a concorrência ilícita e nos crimes de violação de marcas, previstos na Lei 9.279/96, bem como nas sanções às violações do Direito Autoral, previstas na Lei 9.610/98.

Com isso, além da coerção administrativas às violações dos bens da propriedade intelectual, também estariam sendo preservados os direitos do titular do domínio, agora inseridos em um âmbito maior, o da coerção de atos ilícitos. Isso porque os fundamentos que sustentam a punição dos crimes de concorrência desleal não estão na proteção do lucro, mas sim da harmonia nas relações empresariais, tal como destaca Pontes de Miranda (2013, p. 419):

Tem-se dado como fundamento para a repressão da concorrência desleal: a) a necessidade de se proteger o concorrente honesto; b) a punição, no plano do direito penal e no plano do direito privado e administrativo, do concorrente desleal, por se tratar de ato ilícito absoluto, como os outros; c) evitar-se o que possa tirar ao público a livre escolha do que quer adquirir, guardando-o, portanto, contra o emprego de meios desleais.

Considerando esses fundamentos, o legislador definiu no artigo 195 da Lei 9.279/96 um rol de condutas delituosas, que reputa ilícitas, punidas com pena de detenção, de 3 (três) meses a 1 (um) ano, ou multa, destacando-se as seguintes figuras: desviar clientela; usar ou imitar expressão ou sinal de propaganda alheios, criando confusão entre os consumidores; usar, indevidamente, nome comercial, título de estabelecimento ou insígnia alheios ou vender, expor ou oferecer à venda ou ter em estoque produto com essas referências.

Destacando-se, inclusive, que a utilização indevida de nomes protegidos pela propriedade intelectual também caracteriza um ilícito civil, ou seja, a violação da concorrência tratada nessa legislação também implica em consequências patrimoniais. O direito subjetivo à reparação é assegurado ao lesado sem qualquer prejuízo à ação penal, tal como descreve o artigo 207 da Lei 9.279/96, desde que demonstrado o prejuízo, levando-se em consideração os aspectos gerais da responsabilidade civil, pois "o objetivo fundamental da responsabilidade civil é justamente a reparação dos danos causados. Sem danos, poderá haver concorrência desleal, mas não há modo de recorrer ao instituto da responsabilidade civil.” (ASCENSÃO, 2002, p. 206) 
Isto implica em reconhecer, por fim, que as marcas, sinais de propaganda e os domínios de internet possuem relação entre si, sendo lícito aos detentores da propriedade intelectual preservar seus direitos de propriedade também no universo virtual, com a consequente extensão aos registros de domínio, impedindo assim a ação de free rideers. Por outro lado, os titulares das marcas devem respeitar o princípio da especialidade, não lhes sendo permitido impedir o uso de nomes de domínio quando estes estiverem vinculados a atividades econômicas diversas, salvo no caso das marcas notórias. Estas tutelas jurídicas serão balizadas sempre por parâmetros concorrenciais, quais sejam a possibilidade de causar erro ou confusão nos consumidores.

\section{CONCLUSÃO}

Não se pode negar que no meio empresarial, a utilização da internet tem se mostrado como um instrumento necessário aos empresários, tanto no sentido de aproximá-los de sua clientela, quanto no sentido de valorizar seus sinais distintivos.

Nesse cenário foi apresentado o fato de que o registro de domínio, as marcas, o título de estabelecimento e os elementos de propaganda da empresa encontram proteção jurídica em naturezas distintas, cuja conexão mereceu análise específica do ponto de vista econômico e da proteção contra a concorrência desleal.

O texto acabou por apresentar algumas respostas, sem a pretensão de esgotar o assunto, de que os nomes de domínio apresentam um papel econômico indispensável ao crescimento da atividade empresária, pois permite ao seu titular comercializar produtos e serviços em locais muito distantes de sua base física.

Ainda restou demonstrado que os nomes de domínio não se apresentam como um simples endereço eletrônico para a aproximação do empresário com os consumidores, pois representam um novo elemento do estabelecimento empresarial: o título de estabelecimento virtual, cujas tutela jurídica deve respeitar as semelhanças com marcas registradas e Direitos autorais, resguardando os princípios da especialidade e da notoriedade.

Por fim, chegou-se à conclusão de que seria possível aplicar as mesmas regras de proteção da propriedade intelectual tanto no universo físico quanto virtual, reconhecendo que as marcas, sinais de propaganda e os domínios de internet possuem relação entre si, com proteção especial, no sentido de impedir a ação de free rideers. 


\section{BIBLIOGRAFIA}

ALECRIM, Emerson. Endereço IP (INTERNET PROTOCOL). Disponível em: http://www.infowester.com/ip.php. Acesso em 20 de junho de 2016.

ALMEIDA FILHO, José Carlos de Araujo e CASTRO, Aldemario Araujo. Manual de Informática Jurídica e Direito da Informática. Rio de Janeiro: Forense, 2005.

ASCENSÃO, José de Oliveira. Concorrência Desleal. Coimbra: Almedina, 2002.

ASQUINI, Alberto, Perfis da Empresa. Tradução COMPARATO, Fábio Konder. Revista de direito mercantil. Paulo, v. 35, n. 104, p. 109-126, 1996.

BARBOSA, Denis Borges. Tratado da Propriedade Intelectual. Rio de Janeiro: Editora Lumen Juris, 2013.

BRANCHER, Paulo. Direito da Concorrência e Propriedade Intelectual. São Paulo: Singular, 2010.

CARVAlHO, Nuno Pires de. A estrutura dos Sistemas de Patentes e Marcas: passado, presente e futuro. Rio de Janeiro: Lumen Juris, 2009.

COELHO, Fabio Ulhoa. Curso de Direito Comercial. v.1, 16 ed. São Paulo: Saraiva, 2012. Curso de Direito Comercial. v.3, 13 ed. São Paulo: Saraiva, 2012.

DANTES, Alexandre Castro. A proteção das marcas no Brasil: o direito do titular da marca de impedir, a qualquer tempo, o uso ilegal por terceiros. Direito, inovação, propriedade intelectual e concorrência [Recurso eletrônico on-line] organização CONPEDI/ UFMG/FUMEC/Dom Helder Câmara; coordenadores: Maraluce Maria Custódio, João 
Marcelo de Lima Assafim - Florianópolis: CONPEDI, 2015. Disponível em: http://www.conpedi.org.br/publicacoes/66fs1345/2oq57zr8/4Nou9Z83eKGbCLi0.pdf. Acesso em 20 de agosto de 2016.

DE LUCCA, Newton. Aspectos Atuais da Proteção aos Consumidores no Âmbito dos contratos informáticos e telemáticos. In DE LUCCA, Newton e SIMÃO FILHO, Adalberto (coord.) Direito \& Internet: aspectos jurídicos relevantes. São Paulo, Quartier Latin, 2008.

FORGIONI, Paula. Nome de Domíno e título de estabelecimento: nova função para um antigo instituto. In DE LUCCA, Newton e SIMÃO FILHO, Adalberto (coord.) Direito \& Internet: aspectos jurídicos relevantes. São Paulo, Quartier Latin, 2008.

MAMEDE, Gladston. Direito Empresarial Brasileiro: empresa e atuação empresarial. v. 1.. São Paulo: Atlas, 2004.

MENDONÇA, José Xavier Carvalho de. Das firmas ou Razões Comerciais. Atualizado por ZANATA JÚNIOR, Flávio Luiz. Sorocaba-SP: Minelli, 2008.

MIRANDA, Pontes de. Tratado de Direito Privado. Tomo XVII Direito das coisas: propriedade mobiliária (bens incorpóreos). Propriedade Industrial (sinais distintivos). São Paulo: Revista dos Tribunais, 2013.

PINHEIRO, Patricia Peck. Direito Digital. 2 ed. São Paulo: Saraiva, 2008.

RÜCKER, Bernardo. Aspectos jurídicos do domínio de internet. Disponível em: http://www.buscalegis.ufsc.br/revistas/files/anexos/3615-3609-1-PB.htm. Acesso em 15 de agosto de 2016.

SCUDELER, Marcelo Augusto. Do Direito das Marcas e da Propriedade Industrial. 2 ed. Campinas - SP: Servanda,2013. 2007.

VIVANTE, Cesare. Instituições do Direito Comercial. Sorocaba - SP: Minelli, 